\title{
POR QUE ASILAMOS NOSSOS VELHOS
}

\author{
Clarice Oliveira ${ }^{1}$
}

OLIVEirRA, C. Por que asilamos nossos velhos. Rev. Bras. Enf., Brasília, 38(1): 7-13, jan./mar. 1985.

\begin{abstract}
RESUMO. O estudo analisa o resultado de uma pesquisa sobre a problemática do idoso asilado, no Estado da Bahia, as repercussões desta situação na família e na comunidade e a participação da Enfermagem no contexto assistencial das instituições asilares. Parte do princípio de que o homem, em todo o seu ciclo vital, te m necessidade de desenvolver relacionamentos interpessoais. Na velhice, muitos desses relacionamentos são cortados, principalmente quando se estabelece uma condição de isolamento compulsório pela situação asilar. A família, que tradicionalmente tem-se responsabilizado pelos seus velhos, passa a delegar os seus cuidados a uma instituição especializada. Os dados, que foram levantados em 4 instituições asilares, sendo 2 da capital e 2 do interior, são discutidos sob o prisma de uma assistência de enfermagem mais qualificada.
\end{abstract}

ABSTRACT. The research findings about the problematic of aged living in an asylum in the State of Bahia, the repercussion of this situation in the family and community and the participation of nursing in the assistance context of Asylum Institution are analysed in this study. The work was based on the principle of what the man in every his vital cycle has need to develop interrelations. In the aged, much of these relationships are cuted, mainly been when a condition of isolation compulsive by Asylum Institution is established. The family, what traditionally has been responsible by their aged transfer care for specialized institutions. The data obtained in four Asylum Institutions, two from capital, and two from interior, are discussed under the prism of a nusing assistance more qualify.

\section{INTRODUÇÃO}

A familia, no seu conceito mais amplo, é constituída por pessoas interligadas por escalas de valores e desempenho de papéis determinados e sucessivamente delegados aos descendentes. Vários grupos etários estão envolvidos na unidade familiar, proporcionando uma seqüência de idéias, atitudes e comportamentos determinados pelos padrões sociais vigentes e pelas próprias condições sócio-econômicas e culturais do grupo social.
O surgimento de uma nova vida na familia, o nascimento, é geralmente acompanhado de motivo de profunda alegria, partilhada por todos os seus elementos.

A morte causa a quebra da harmonia vivencial da família, senão definitivamente, pelo menos enquanto durar o período de adaptação à condição da perda.

Neste contexto, os indivíduos lutam, vivem, amam, envelhecem e morreın.

Enquanto criança, o homem desfruta do pri-

1 Professor Adjunto da EEUI:BA. Livre-docente e Doutora pela EEAN-UFRJ. 
vilégio de ser protegido e estimulado a preparar-se para o desempenho de tarefas futuras.

$\mathrm{Na}$ idade adulta, o ser humano assume os seus mais importantes papéis - trabalhar, amar, gerar, criar e preparar os filhos para a vida.

Desde o nascimento, o homem trava gradativos contatos com vários grupos sociais representados pela familia, escola, trabalho, lazer, vizinhança, igreja e, com cada um, desenvolve experiências vivenciais que determinam diferentes papéis. Estes papéis são assumidos de maneira natural e conferem maior ou menor significado à vida.

Sabe-se que quan to mais papéis desempenhar o indivíduo mais crescerá o seu prestígio e importância na sociedade e maior será a sua função na comunidade em que vive.

$O$ apogeu dos papéis vivenciais registra-se na idade adulta. Alguns autores referem que, dos 40 aos 70 anos, o homem está apto a desenvolver a sua maior produção intelectual ao lado de uma imensa experiência de vida que lhe permite contribuir para o progresso da sociedade e o desenvolvimento da sua espécie.

No entanto, para que haja crescimento humano significativo, torna-se necessário enfrentar-se sucessivos desafios, os quais representam a própria essência de viver.

A velhice, por ser a última etapa da vida, está fadada ao afastamento dos desafios profissionais pela aposentadoria e dos desafios sociais pela perda progressiva dos papéis na sociedade.

Ao mesmo tempo, os desafios familiares e domésticos são substituídos por uma complacente tolerância, pelos demais elementos da familia, para com o idoso.

Sentindo-se desnecessário para o trabalho e dispensável para a decisão e condução familiar, resta ao velho duas alternativas: rebelar-se, tornando-se um elemento desajustado, ranzinza e desagradável, ou acomodar-se na sua profunda solidão e expectativa da morte breve.

O enfraquecimento destas características sociais não elimina, porém, os elementos básicos da identidade do idoso como pessoa e como ser social.

Este é o conflito: enquanto a sociedade o relega, o idoso ainda mantém-se integrado psiquicamente à sua conjuntura.

A família conflitada não encontra espaço para o seu velho, seja pela nova modalidade de moradia em pequenos apartamentos, seja pelas condições de trabalho que exigem o afastamento dos adultos e jovens para atividades profissionais.
O orçamento familiar nem sempre prevê despesas com a saúde do idoso, por si mesmo mais suscetível às alterações de saúde, e a manutenção de um acompanhante para o idoso sadio ou doente, além de onerosa, exige condições de preparo que a nossa sociedade não está acostumada a assumir.

Acrescido a tudo isto, o velho, se não é muito velho ou doente, permanece com o sentido de autodeterminaçao e nem sempre aceita ter alguém estranho para prestar-lhe assistência em domicílio.

Pela nossa vivência junto aos idosos e seus familiares, observamos que estes aspectos abordados fazem com que a familia opte por internar o velho em abrigo ou qualquer instituição de assistência à velhice.

$\mathrm{O}$ abrigo recebe assim um idoso que, além da problemática inerente ao processo do envelhecimento, traz consigo toda esta carga de carências docorrente da transformação familiar.

Além disso, é retirado bruscamente do seu meio familiar, onde passou uma longa vida e colocado numa instituição onde vai conviver com pessoas de sua faixa etária, ou mais velhas, totalmente estranhas ao seu convívio social.

Por outro lado, as instituições que se destinam a assistir idosos, estão muito aquém do desejado para o atendimento às necessidades peculiares a este contingente da nossa sociedade, por si mesmo carente e solitário, destinado à inércia e ao tédio.

\subsection{OBJETIVOS}

- Identificar os fatores que determinam a internação de idosos em instituições de assistência à velhice.

- Obter dados para o planejamento da assistência de enfermagem a ser desenvolvida jun to aos idosos asilados e seus familiares.

\section{REFERENCIAL TEÓRICO}

O grupo etário que constitui a velhice, está formado por pessoas que partilham características distintas dos demais indivíduos dos outros grupos e tários.

Distingue-se o velho como vítima de desvantagens, pelas deficiências físicas, mentalidade retrógrada, isolamento, pobreza e negligência, constituindo-se portanto num "problema social".

Dependente da população adulta para suporte 
econômico e de contorto, e ameaçando a demanda geral de recursos com os quais a sociedade está desejando satisfazer outras necessidades, sua imagem é de dupla face estereotipada - obje to de compaixão e de encargo para o Estado.

A população idosa está realmente predisposta às degenerações e doenças biológicas. Está separada pela morte ou distância de familiares e amigos e privada da capacidade e da oportunidade de continuar um empreendimento produtivo. E como o número de velhos torna-se cada vez maior, também os custos com a infra-estrutura para atendimento às suas necessidades cresce. Sem este suporte não pode o idoso ter uma vida sadia e independente, requerendo hospitalização e maior gasto com serviços de saúde, transformando o processo em um ciclo vicioso.

A Gerontologia tenta explicar o processo do envelhecimento através da formulação de várias teorias, ao tempo em que busca encontrar as ações adequadas para a prevenção de condições indesejáveis nos campos físicos, psíquicos e sociais dos indivíduos que atingiram a terceira idade.

Procura eliminar os estereótipos formados através de longas etapas históricas, procurando enfatizar a aceitação das diferenças individuais e sociais e as distintas condições internas e externas do envelhecer.

Conquan to o interesse pelo conhecimen to científico do envelhecimento tenha surgido nas últimas décadas, com grande ênfase, em todas as áreas do saber, a necessidade de conhecer o significado da idade remonta a muitos séculos.

Cada civilização conceitua o seu velho dentro de seus padrões culturais.

A industrialização e a urbanização proporcionaram profundas modificações na vida humana e, conseqüentemente, também, na conceituação e aceitação do velho na sociedade.

Como refere ACUÑ ${ }^{1}$, "o processo de envelhecimento da população e das necessidades dos velhos nos países em desenvolvimento devem relacionar-se com atitudes culturais também em evolução. É o caso por exemplo do impacto que a incorporação da mulher nas forças de trabalho e o processo de migração às áreas urbanas está produzindo na estrutura tradicional da família".

No Brasil, a população de idosos, pelos dados do último Censo, é de 7\%, o que corresponde aproximadamente a 8 milhões de pessoas com mais de 60 anos de idade.

Enquanto o fator tempo é a variável na idade cronológica, o conceito da vida biológica abrange, além do número de anos, condiçōes que aceleram ou retardam o ritmo de senescência.

Afirma-se que a mulher vive mais que o homem, embora o seu processo de envelhecimento seja mais rápido. Atualmente, a estimativa de vida é calculada em 60 anos para os homens e 65 para as mulheres. Espera-se atingir os 70 e. 75 , respectivamente, até o final do século.

A enfermagem gerontológica e geriátrica tem como objetivo a saúde e o bem-estar do idoso, o qual tem necessidades básicas afetadas e determinadas pelo processo do envelhecimento além de possuir problemas terapêuticos e de reabilitação bem peculiares.

HARDY $^{9}$ cita cinco requisitos básicos para os idosos viverem bem: vida independente, casa, ocupação ou ser necessário, af eição e comunicação.

\section{METODOLOGIA}

\subsection{CARACTERISTICAS DAS INSTITUIÇÕES PESQUISADAS}

A pesquisa foi desenvolvida em quatro instituições asilares de assistência ao idoso, sendo duas localizadas na Capital e duas em cidades do interior do Estado da Bahia.

A coleta de dados foi feita entre novembro de 1982 e junho de 1983.

As instituições escolhidas têm características semelhantes e essa escolha deveu-se à intenção de estabelecer um estudo comparativo entre os asilados interioranos e os da Capital.

Foram codificadas, para efeito de sigilo, em instituições $A, B, C$ e $D$, estando as duas primeiras localizadas na Capital e as outras no interior.

Todas as instituições abrigam idosos de ambos os sexos e não têm fins lucrativos. Têm como critério a admissão de pessoas com idade acima de 60 anos e que não sejam portadoras de doenças incapacitantes.

A instituição $A$ tem capacidade para 350 internos, com média de ocupação de $80 \%$, sendo $69 \%$ do sexo feminino e $11 \%$ do sexo masculino. Tem caráter filantrópico, sendo mantida por renda de bens patrimoniais por associação beneficente e alguns leitos da Prefeitura e da Legião Brasileira de Assistência.

Tem um Conselho Deliberativo, constituído de 50 conselheiros, os quais elegem a Diretoria. 0 presidente da Diretoria administra diretamente 
a instituição juntamente com irmãs religiosas que exercem tarefas gerenciais.

O abrigo dispõe ainda de dois médicos, dois odontólogos, uma assistente social e, na parțe de enfermagem, de uma auxiliar de enfermagem e oito atendentes.

A instituição $B$ tem capacidade para 395 internos com média de ocupação de $95 \%$, sendo $64 \%$ do se xo feminino e $36 \%$ do sexo masculino.

É mantida pela Prefeitura de Salvador e está subordinada à Secretaria Municipal de Saúde. Tem um Diretor e duas Chefias: Administrativa e Técnica-Profissional.

Dispōe de seis médicos, um odontólogo, cinco assistentes sociais, duas farmacêuticas, uma nutricionista, dois terapeutas ocupacionais e uma equipe de enfermagem composta de uma enfermeira e quatro auxiliares de enfermagem e alguns atendentes e serviçais.

A instituição $C$ é filantrópica e tem capacidade para 60 internos com média de ocupação de $90 \%$, sendo $70 \%$ do sexo feminino e $30 \%$ do sexo masculino.

Tem um Conselho Diretor, cujo presidente é responsável pela administração geral da instituição. Toda a parte gerencial está a cargo de irmãs religiosas, bem como a parte assistencial dos idosos sadios e doentes.

Não dispõe de enfermeira. Além das religiosas alguns atendentes e serviçais exercem a assistência.

Dispõe de dois médicos e já teve assistente social em seu quadro, mas no momento da pesquisa não dispunha de nenhuma.

A instituição $D$ tem capacidade para 65 internos com média de ocupaçāo de $99 \%$, sendo $70 \%$ do sexo feminino e $30 \%$ do sexo masculino. É mantida por associação beneficente e conta com ajuda governamental.
Dispõe de uma diretoria composta de Presidente, Vice-Presidente, Secretária, Diretor Interno e Tesoureiro.

Conta com um médico, duas auxiliares de enfermagem, além das irmãs religiosas que gerenciam as atividades gerais.

Todas as instituições servem de campo de estágio para estudantes da área de saúde e, especificamente, para estudantes de enfermagem.

\subsection{SELEÇÃO DA AMOSTRA}

Foram selecionados os idosos com 60 anos ou mais de idade, de ambos os sexos, residentes nas instituições $A, B, C$ e $D$, em condições de prestar informações para preenchimento do instrumento.

A princípio, a amostra estava restrita aos idosos que eram visitados por familiares e/ou amigos, pois a pesquisa incluía uma população constituída de informantes que tivessem vínculo de parentesco ou de amizade com os idosos.

Tornou-se impossível a realização desta etapa em vista da recusa explícita e irredutível dos parentes e mesmo dos amigos dos idosos em prestar qualquer esclarecimento para preenchimento do questionário. Mesmo depois de um exaustivo trabalho de conquista desta população, conseguiu-se apenas preencher alguns questionários, motivo pelo qual foi anulado.

Será apenas analisada a observação feita pelos pesquisadores sobre a reação desses indivíduos.

$\mathrm{O}$ instrumento foi testado em duas instituições e sofreu modificações de acordo com as falhas observadas.

Compõem a população de estudo, 45 idosos da Instituição $A, 45$ da Instituição $B, 30$ da Instituição $C$ e 20 da Instituição $D$.

TABELA 1 - Distribuição da População Estudada por Instituição e por Sexo - junho 1983

\begin{tabular}{l|r|r|r|r|r|r|r|r|r|r}
\hline \multirow{2}{*}{ Sexo } & \multicolumn{2}{|c|}{ Instituição } & \multicolumn{2}{|c|}{ A } & \multicolumn{2}{|c|}{ C } & \multicolumn{3}{|c|}{ D } & \multicolumn{3}{|c}{ Total } \\
\cline { 2 - 11 } & No & $\%$ & No & $\%$ & No & $\%$ & No & $\%$ & No & $\%$ \\
\hline Masculino & 12 & 36,6 & 11 & 24,4 & 13 & 43,3 & 07 & 35,0 & 43 & 30,7 \\
Feminino & 33 & 73,4 & 34 & 75,6 & 17 & 56,7 & 13 & 65,0 & 97 & 69,3 \\
\hline Total & 45 & 100,0 & 45 & 100,0 & 30 & 100,0 & 20 & 100,0 & 140 & 100,0 \\
\hline
\end{tabular}


A coleta de dados foi realizada pela autora e por estudantes e professores de enfermagem que se voluntariaram para o trabalho, além de alunas bolsistas de pesquisa.

Foram estudados, no total, 140 idosos de ambos os sexos.

O estudo foi autorizado pelas autoridades competentes de todas as instituições e todos os elementos da equipe de saúde atuantes nos campos foram informados sobre a realização do trabalho.

\section{ANÁLISE E DISCUSSÃO DOS RESULTADOS}

A pesquisa foi prejudicada pela preocupação demonstrada pelos respondentes em fornecer os dados. Referiam não desejarem indispor-se com os dirigentes das instituições e que temiam perder o direito de continuar residindo no abrigo e usufruindo dos benefícios que lhes săo conferidos.

O questıonário foi aplicado através de entrevista dos pesquisadores com os idosos, depois de cuidadosa preparação no sentido de assegurar-lhes o sigilo das informações colhidas, quanto à identificação do informante.

A população foi constituída de 140 idosos dis- tribuídos por sexo em $30,7 \%$ do sexo masculino e $69,3 \%$ do sexo feminino.

0 maior percentual de idosos em abrigos correspondeu aos solteiros $55,0 \%$, sendo do sexo masculino predominante em $62,8 \%$ seguidos dos casados em $20,9 \%$. No sexo feminino predominando em $52,7 \%$ os solteiros e $40,0 \%$ os viúvos.

Não foi registrado nenhum respondente desquitado.

No geral do estudo, o percentual de respondentes da capital foi superior a todos os outros, o que não ocorreu com as instituições isoladas.

Através da Tabela 4, observa-se um percentual decrescente em relação à freqüência de visita de familiares aos idosos asilados. Do sexo masculino, $37,2 \%$ não recebem visitas e $23,2 \%$ recebem eventualmente. Somente $2,4 \%$, diariamente. Do sexo feminino, $46,5 \%$ recebem eventualmente e $17,5 \%$ não são visitados. No total, apenas $1,5 \%$ é visitado diariamente enquanto que $39,3 \%$, apenas eventualmente e $23,6 \%$ não recebem visitas de familiares.

Nāo foram computadas visitas realizadas por voluntários, isto é, pessoas que se dedicam a visitar idosos asilados, seja com sentido humanitário ou religioso.

TABELA 2 - População amostrada, segundo o sexo e o estado civil - junho 1983

\begin{tabular}{l|c|c|c|c|c|c}
\hline \multirow{2}{*}{ Sexo } & \multicolumn{2}{|c|}{ Masculino } & \multicolumn{2}{c|}{ Feminino } & \multicolumn{2}{c}{ Total } \\
\cline { 2 - 7 } Estado Civil & No & $\%$ & No & $\%$ & No & $\%$ \\
\hline Solteiro & 27 & 62,8 & 50 & 52,7 & 77 & 55,0 \\
Casado & 9 & 20,9 & 8 & 8,2 & 17 & 12,1 \\
Viúvo & 7 & 16,3 & 39 & 40,0 & 46 & 32,9 \\
Desquitado & - & - & - & - & - & - \\
\hline Total & 43 & 100,0 & 97 & 100,0 & 140 & 100,0 \\
\hline
\end{tabular}

TABELA 3 - População amostrada, segundo o sexo e a procedência - junho 1983

\begin{tabular}{l|c|c|c|c|c|c}
\hline \multirow{2}{*}{ Sexo } & \multicolumn{2}{|c|}{ Masculino } & \multicolumn{2}{c|}{ Feminino } & \multicolumn{2}{c}{ Total } \\
\cline { 2 - 7 } Procedência & No & $\%$ & No & $\%$ & No & $\%$ \\
\hline Capital & 24 & 55,8 & 50 & 51,5 & 74 & 52,9 \\
Interior & 15 & 34,8 & 42 & 43,3 & 57 & 40,7 \\
Outro Estado & 4 & 9,3 & 5 & 5,2 & 9 & 6,4 \\
\hline Total & 43 & 100,0 & 97 & 100,0 & 140 & 100,0 \\
\hline
\end{tabular}


TABELA 4 - Freqüência de visitas de familiares aos idoso asilados - junho 1983

\begin{tabular}{l|c|c|c|r|r|r}
\hline \multirow{2}{*}{ Vexo } & \multicolumn{2}{|c|}{ Masculino } & \multicolumn{2}{c|}{ Feminino } & \multicolumn{2}{c}{ Total } \\
\cline { 2 - 7 } & No & $\%$ & No & $\%$ & No & $\%$ \\
\hline Diariamente & 1 & 2,4 & 1 & 1,0 & 2 & 1,5 \\
l vez por semana & 3 & 7,0 & 15 & 15,5 & 18 & 12,8 \\
2 vezes p/ semana & 4 & 9,3 & 10 & 10,3 & 14 & 10,0 \\
Mensalmente & 9 & 20,9 & 9 & 9,2 & 18 & 12,8 \\
Eventualmente & 10 & 23,2 & 45 & 46,5 & 55 & 39,3 \\
Não é visitado & 16 & 37,2 & 17 & 17,5 & 33 & 23,6 \\
\hline Total & 43 & 100,0 & 97 & 100,0 & 140 & 100,0 \\
\hline
\end{tabular}

Verifica-se na Tabela 5 que o item referente à vinda "espontânea" para o abrigo tem os mais altos percentuais tanto no sexo masculino, $60,5 \%$, quanto no sexo feminino, $80,5 \%$. Estes resultados podem também estar relacionados com a necessidade que têm os velhos asilados de assegurar o seu lugar no abrigo e a insegurança quanto ao sigilo das informações, o que poderia levá-los a uma perda do espaço existencial.

Quanto aos itens "obrigada" e "enganada" foram computados isoladamente, pois registrou-se a ocorrência de situações em que idosos sabiam que seriam asilados e não tinham opção devido às contingências. Em outros, os idosos recusaram-se a morar no abrigo e foram levados por familiares ou responsáveis até a instituição, sedados ou informados de que iriam apenas passear.

Os resultados da Tabela 6 mostram que $81,4 \%$ dos idosos do sexo masculino e $73,2 \%$ do sexo feminino afirmam que têm amigos dentro do abrigo.

Tanto os que responderam afirmativa quanto negativamente foram solicitados a justificar a resposta. Foram registradas justificativas tais como: "Sim. Todos são companheiros e a Irmã quer ver todos unidos". "Sim porque moramos juntos". Ou então: "Não. São colegas de quarto por serem obrigados. São falsos". "Não, pois não existe comunidade".

TABELA 5 - Condição de entrada no abrigo, segundo a opçaõ dos idosos e o sexo - junho 1983

\begin{tabular}{l|c|c|c|r|r|r}
\hline \multirow{2}{*}{$\begin{array}{l}\text { Vinda para Sexo } \\
\text { o Abrigo }\end{array}$} & \multicolumn{2}{|c|}{ Masculino } & \multicolumn{2}{c|}{ Feminino } & \multicolumn{2}{c}{ Total } \\
\cline { 2 - 7 } & No & $\%$ & No & $\%$ & No & $\%$ \\
\hline Espontânea & 26 & 60,5 & 78 & 80,5 & 104 & 74,3 \\
Obrigada & 7 & 16,3 & 16 & 16,5 & 23 & 16,4 \\
Enganada & 10 & 23,2 & 3 & 3,0 & 13 & 9,3 \\
\hline Total & 43 & 100,0 & 97 & 100,0 & 140 & 100,0 \\
\hline
\end{tabular}

TABELA 6 - Opiriião dos idosos sobre relações de amizade entre os asilados - junho 1983

\begin{tabular}{l|c|c|c|c|c|c}
\hline \multirow{2}{*}{$\begin{array}{l}\text { Tem amigos } \\
\text { Sexo Abrigo }\end{array}$} & \multicolumn{2}{|c|}{ Masculino } & \multicolumn{2}{c|}{ Feminino } & \multicolumn{2}{c}{ Total } \\
\cline { 2 - 7 } no & No & $\%$ & No & $\%$ & Nọ & $\%$ \\
\hline Sim & 35 & 81,4 & 71 & 73,2 & 106 & 75,7 \\
Não & 8 & 18,6 & 26 & 26,8 & 34 & 24,3 \\
\hline Total & 43 & 100,0 & 97 & 100,0 & 140 & 100,0 \\
\hline
\end{tabular}


Vários referiram que os amigos eram os companheiros que os ajudavam a se locomover (incapacitados físicos) ou nas doenças. Outros referiram que "há necessidade de ter alguém com quem conversar ou com quem desabafar".

\section{CONCLUSÃO}

A manutenção de idosos em abrigos tem sido assunto de muịta discussão pelos estudiosos da área geron tológica.

No presente estudo foram levantadas algumas questões sobre os fatores que levam a familia, como núcleo tradicionalmente responsável pelo idoso, a decidir-se pela colocação do mesmo em instituição assistencial especializada. Por outro lado, foram analisados os dados obtidos com a aplicação de um formulário a 140 idosos, de quatro abrigos, sendo dois localizados em Salvador e dois em cidades do interior da Bahia.

Dos resultados obtidos conclui-se que a grande maioria de idosos abrigados registra desejos de continuar na instituição por ter atingido uma fase de acomodação situacional que não the permite outra opção. As questões em aberto proporcionaram respostas tais como: "Pra velhice está bom o abrigo" ou então "Gosto do abrigo porque é um canto meu".

Outros achan que têm que se contentar com o que lhes oferecem porque não têm condições financeiras de terem coisa melhor.

Referem-se ainda ao pequeno espaço que lhes é destinado, perda da privacidade por não disporem de quartos separados e por não poderem desenvolver atividades lucrativas.

Diante da problemática exposta, verifica-se a premência de reformulação dos princípios que norteiam a conduta da farnília e da comunidade face ao idoso e ao processo de envelhecimento.

A preparação individual para a velhice, bem como a oferta de melhores condições de vida para o velho é assunto para uma profunda reflexão e para futuras decisões governamentais.

Os países que possuem grande número de pessoas idosas, têm, nos últimos anos, adotado políticas de proteção à velhice. Condizentes com a própria visão que têm 'da velhice, tais políticas baseiam-se no paternalismo e na exclusão social. $O$ trabalho é assim considerado uma carga demasiado penosa para as pessoas idosas. As pessoas em idades cada vez mais prematuras passam a reivindicar pensões e aposentadorias, proporcionando assim o aumento e crescimento de instituições geriátricas devido aos problemas que o ócio pode trazer. É de se esperar que, nestas instituições, os velhos tenham boa habitação, recreação, assistência social e, naturalmente, atençāo médica e de enfermagem adequadas.

\section{- Agradecimentos}

A autora apresenta agradecimentos às Instituições de Assistência aos Idosos que se colocaram à disposição para esta pesquisa e às professoras e alunas de enfermagem que colaboraram na coleta de dados e apresentaram sugestōes para este trabalho.

OLIVEIRA, C. Why we asylum our aged. Rev. Bras. Enf., Brasília, 38(1): 7-13, jan./mar. 1985.

\section{REFERẼNCIAS BIBLIOGRĀFICAS}

1. ACUÑA, H. R. La salud de las personas de edad avanzada. Bol. Of. Sanit. Panam., 91(3):189-190, sept. 1981.

2. BURNSIDE, I. M. Enfermagem e os idosos. São Paulo, Organização Andrei, 1979.

3. DALL, J. L. Helping old people to continue living at home! the contribution of the day hospital. Roy. Soc. Hlth J., London, 1978.

4. DE LONG, A. J. Environment for the elderly. 24(4): 101-12, 1974. J. Commun, Mitwarekee.

5. DUPUS, P. H. Old is beautiful. Nurs. Outlook, New York, 18(8): 25-27, A ug. 1970.

6. FENNESSY, C. M. Nursing care of aged patient. Hosp. Progr., Saint Louis, 51: 46-50, jan. 1970.

7. FERREIRA, P. C. A. Velhice e hospitalização. Ars. Curandi, São Paulo, 11(1): 42-58, mar. 1978.

8. GOLDSTONE, H. Helping old people to continue living at home! stope look, linter. Roy. Soc. Hlth. J., London, 98(1): 15-18, Feb. 1978.

9. HARDY, S. Voluntary service and the elderly. Nurs. Mirror, Sussex, 132(2): 12-13, jan. 81971.

10. MORGAN, A. J. \& MORENO, J. W. La práctica de enfermeria de salud mental. Colombia, Carvajal, 1973. 